\title{
Chromatographic approach to study the configurational stability of Ni(II) complexes of amino-acid Schiff bases possessing stereogenic nitrogen
}

\author{
Han, J. L. \\ Jean, $M$. \\ Roussel, C. \\ Moriwaki, $\mathrm{H}$. \\ Soloshonok, V. A.
}

\begin{abstract}
Herein, we disclose the design of a model Ni(II) complex of glycine Schiff base possessing single-nitrogen stereogenic center, which was successfully used for high-performance liquid chromatography (HPLC)-assisted assessment of its configurational stability. The major finding is that the configurational stability of the $\mathrm{Ni}$ (II)-coordinated nitrogen is profoundly dependent on the reaction conditions used, in particular the solvent, and can range from inconsequential ( $t_{1 / 2}$ less than $5 \mathrm{~min}$ ) to virtually completely stable $\left(t_{1 / 2} 90 \mathrm{y}\right)$. The discovery reported in this study most likely to be of certain theoretical and synthetic value.
\end{abstract}

\section{1 | INTRODUCTION}

Amino acids (AAs) are among a few essential compounds intricately involved in some basic aspects of the phenomenon of life. They played a momentous role in the development of organic, bio-organic, medicinal, and pharmaceutical chemistry shaping up the modern healthcare industry and life sciences. ${ }^{1}$ Nowadays, the use of tailor-made ${ }^{2}$ AAs in the design of peptides/ peptidomimetics with restricted number of conformations and precise positioning of the side chains in the $\chi$-space ${ }^{3}$ is a well-established paradigm in the design of modern pharmaceuticals. ${ }^{1,4,5}$ Consequently, the current interest in chemistry of tailor-made $\mathrm{AAs}^{6}$ and their analogs, in particular fluorine-containing, ${ }^{7}$ sulfonic, ${ }^{8}$ and phosphonic ${ }^{9}$ derivatives, is at an all-time high, exploring new structural ideas, functions, and bio-properties. Consistent with our long-standing interest in asymmetric synthesis of tailor-made $\mathrm{AAs}^{10}$ and their nonlinear chiroptical properties, such as self-disproportionation of enantiomers, ${ }^{11}$ we were actively contributing to the development of the Ni(II) complex chemistry of AA Schiff 
bases as a generalized methodology for preparation of various types of tailor-made AAs (Scheme 1). ${ }^{4,6,12}$

As shown in Scheme 1, generally represented ligand $(S)$ - or $(R)-\mathbf{1}$, bearing stereochemical information on one of their structural elements, can be transformed into the corresponding glycine derivative or used directly for complexation with AAs. The latter case can be used for the deracemization, dynamic kinetic resolution, or $(S)$ to $(R)$ interconversion of unprotected $\alpha$ - and $\beta$-AAs. ${ }^{13,14}$ On the other hand, the square-planar Gly-Ni(II) complex 2 serves as a useful chiral nucleophilic glycine equivalent to be transformed into the intermediates $\mathbf{3}$ via homologation with variety of electrophilic reagents. Typically used reaction types include alkyl halide alkylations, ${ }^{15}$ Michael, ${ }^{16}$ aldol, and Mannich ${ }^{17}$ addition reactions. Compounds 3 can be disassembled under operationally convenient conditions to afford AAs of general types $\mathbf{4}$ to $\mathbf{1 0}$ along with recovery of chiral ligands $\mathbf{1}$. Using the modular approach to the design of chiral ligands, ${ }^{18}$ recently, we have developed novel types of ligands and the corresponding Gly-Ni(II) complexes exploring different forms of chirality (Figure 1).

For example, complex $\mathbf{1 1}{ }^{19}$ possesses a traditional central chirality located on the $\alpha$-carbon of the proline residue. On the other hand, the stereochemical information in complex $12^{20}$ is provided by the axial chirality of dibenzo-azepin moiety. Curious case of double asymmetric induction is presented by complex $\mathbf{1 3}$ featuring the central along with the axial chirality, resulting from a restricted rotation of the o-chloro-phenyl moiety. ${ }^{21}$ More recently, we developed compounds of type 14, derived

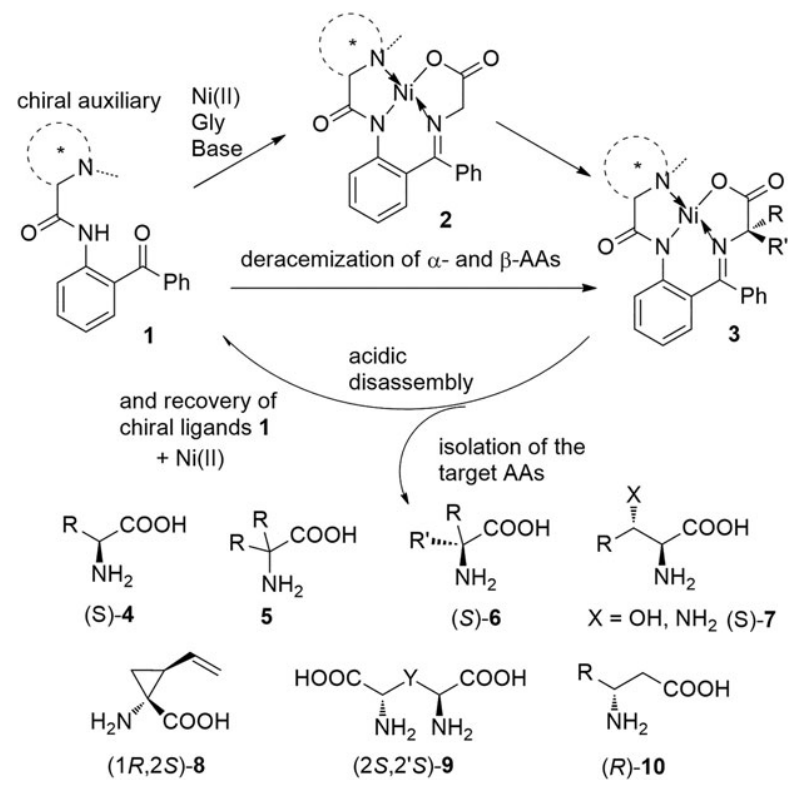

SCHEME 1 General approach for preparation of tailor-made amino acids (AAs) of types $\mathbf{4}$ to $\mathbf{1 0}$ via chiral ligands $\mathbf{1}$ and homologation of nucleophilic glycine equivalents $\mathbf{2}$
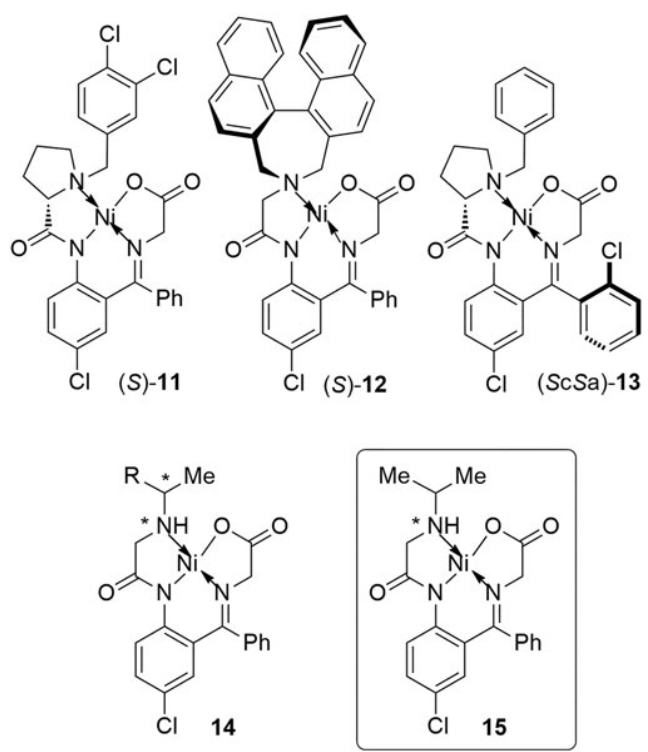

FIGURE 1 Structural types of chiral ligands and the corresponding Gly-Ni(II) complexes $\mathbf{1 1}$ to $\mathbf{1 5}$ of glycine Schiff base

from chiral amines, as a source of stereochemical information. $^{22}$ In particular, application of complexes $\mathbf{1 4}$ allowed us to perform the synthesis of some $\alpha$-AAs using the esoteric case of a second-order asymmetric transformation control. ${ }^{23}$ The rare properties of compounds $\mathbf{1 4}$ were found to result from a combination of configurationally stable stereogenic carbon with configurationally unstable stereogenic nitrogen of the amine residue. To further the synthetic applications of this type of chiral ligands and the corresponding $\mathrm{Ni}(\mathrm{II})$ complexes, we realized that it might be highly desirable to quantify the configurational stability of the stereogenic nitrogen in compounds 14. In this work, we describe synthesis of specially designed complex 15, chiral HPLC-assisted separation of the enantiomers, ${ }^{24}$ and their racemization rates as a measure of configurational stability of the stereogenic nitrogen in $\mathbf{1 5}$.

\section{2 | MATERIALS AND METHODS}

\section{1 | General information}

All commercial reagents were used without additional purification unless otherwise specified. All experiments were monitored by thin-layer chromatography (TLC) using ultraviolet (UV) light as visualizing agent. ${ }^{1} \mathrm{H}$ nuclear magnetic resonance (NMR) $(400 \mathrm{MHz}),{ }^{13} \mathrm{C}$ NMR (101 MHz), and ${ }^{19} \mathrm{~F}$ NMR (376 MHz) were measured on Bruker AVANCE III-400 spectrometer. Melting points are uncorrected. Infrared spectra were obtained on Bruker Vector 22 in $\mathrm{KBr}$ pellets. High resolution mass spectrum (HRMS) was recorded on a LTQ-Orbitrap XL (Thermo Fisher, USA). 


\subsection{General synthetic procedures and experimental methods synthesis of 18}

To a slurry of $\mathbf{1 7}$ ( 1 equiv) and potassium carbonate (1.2 equiv) in acetonitrile was added the corresponding amine (1.1 equiv). The reaction was allowed to proceed for 2 hours at $60^{\circ} \mathrm{C}$ to $70^{\circ} \mathrm{C}$ (monitored by TLC) before the reaction mixture was concentrated under vacuum. Water was added to the viscous liquid, followed by extraction with dichloromethane. The organic portions were combined, dried with magnesium sulfate. The solvent was evaporated to give the crude product $\mathbf{1 8}$, which was purified by flash chromatography (For details, see Supporting Information).

\section{3 | Synthesis of $\mathbf{1 5}$}

An oven-dried reaction vial containing 18 (0.2 mmol), glycine (5 equiv), nickel nitrate hexahydrate ( 2 equiv), and $\mathrm{K}_{2} \mathrm{CO}_{3}$ was evacuated and purged with argon three times. Then, $\mathrm{MeOH}$ ( $4 \mathrm{~mL}$ ) as solution was added via syringe at ambient temperature, respectively. Then, the reaction mixture was stirred for 8 hours at ambient temperature, and then, the reaction was quenched with $\mathrm{H}_{2} \mathrm{O}(5 \mathrm{~mL})$. The organic layer was removed, and the aqueous layer was extracted with $\mathrm{DCM}(2 \times 5 \mathrm{~mL})$. The combined organic layers were washed with $\mathrm{H}_{2} \mathrm{O}(2 \times 10 \mathrm{~mL})$ and brine solution $(1 \times 10 \mathrm{~mL})$ and dried over anhydrous $\mathrm{Na}_{2} \mathrm{SO}_{4}$. The solvent was evaporated to give the crude product 15, which was purified by flash chromatography (For details, see Supporting Information).

\section{3 | RESULTS AND DISCUSSION}

Commercially available o-amino-benzophenone $\mathbf{1 6}$ (Scheme 2) was selectively mono-acylated with bromoacetyl bromide in a solution of acetonitrile, to afford amide 17. Compound $\mathbf{1 7}$ was isolated and reacted with iso-

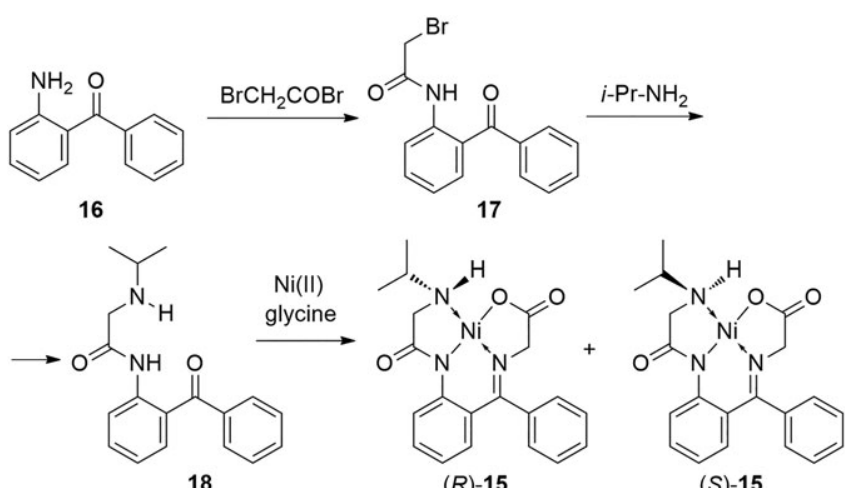

SCHEME 2 Synthesis of ligand $\mathbf{1 8}$ and racemic glycine Schiff base Ni(II) complex 15 containing stereogenic nitrogen propylamine. As was shown previously, ${ }^{25}$ the application of Hünig's base (DIPEA) is essential for preparation of mono-alkylated product 18 in good chemical yield. Synthesis of the target racemic $\mathrm{Ni}(\mathrm{II})$ complex $(R / S)$-15 was performed in methanol starting from ligand 18, glycine, $\mathrm{Ni}(\mathrm{OAc})_{2}$, as a source of $\mathrm{Ni}(\mathrm{II})$ ions, and $\mathrm{Na}_{2} \mathrm{CO}_{3}$ as a base. Complex $(R / S)$-15 was carefully purified by column chromatography on silica gel and fully characterized.

It should be emphasized that separation of enantiomers containing stereogenic $\mathrm{N}-\mathrm{H}$ nitrogen coordinated to a metal, like the type presented by complex 15, has never been described in the literature. Accordingly, while being novel and scientifically exciting, possibility of the separation, detection, and study of the enantiomers of compound 15 was far from certain. Thus, drawing inspiration from our recent study on the chromatographic separation of enantiomers of axially chiral $\mathrm{Ni}$ (II) complexes of glycine and other amino acids, ${ }^{26}$ we proceeded with a comprehensive search for proper chromatographic resolution conditions. Taking advantage of available to us (Marseille group), entirely automated equipment for screening chiral separation conditions (stationary phases, solvents, temperature, and chiroptical detection), we eventually identified reasonably good separation conditions presented in Figure 2.

As one can see from Figure 2, the enantiomers 15 were quite successfully separated over several chiral amylose carbamates stationary phases, such as, Chiralpak IA and ID. These results were a crucial breakthrough in our work as they provided the physical evidence that the enantiomers are sufficiently stable to be separated and collected for off-line studies. Nevertheless, working with the ethanolic solutions of separated enantiomers 15, we observed their tendency to partial racemization at ambient temperatures. Accordingly, we optimized the working procedure in a way that immediately after the preparative chiral HPLC separation, using ethanol as a mobile phase, the separated fractions of enantiomers $\mathbf{1 5}$ were kept and then evaporated at temperatures lower than $5^{\circ} \mathrm{C}$. This procedure allowed us to obtain enantiomers $\mathbf{1 5}$ with excellent excess of substrate (ees).

Having developed a reliable approach for separation of enantiomers $\mathbf{1 5}$, we were in position to perform a comprehensive study of their configurational stability. Following the successful methodology of our previous chromatographic study of axially chiral $\mathrm{Ni}$ (II) complexes, ${ }^{26}$ the racemization of enantiomer $\mathbf{1 5}$ was followed at a particular temperature by monitoring the enantiomeric ratios as a function of time. The enantiomerization (racemization) rate was deduced from the slope of the first-order kinetic line. The results obtained are presented in Table 1.

As mentioned above, enantiomers $\mathbf{1 5}$ were found to be relatively stable in ethanolic solutions allowing their 


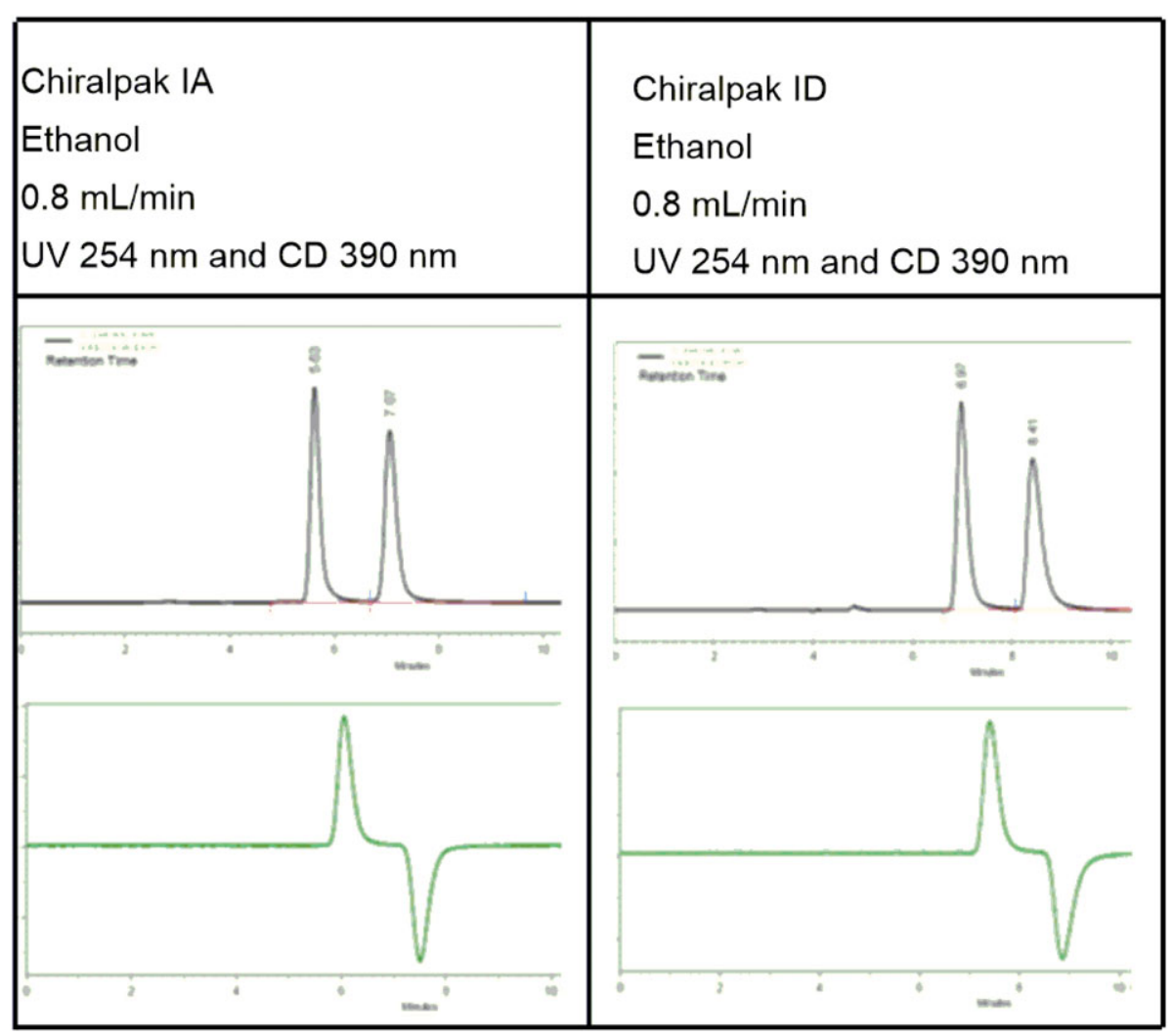

FIGURE 2 Room temperature separation of enantiomers of Ni(II) complex 15 on Chiralpak IA and Chiralpak ID columns

TABLE 1 Enantiomerization barriers and half-live time for enantiomer 15 in different solvents

\begin{tabular}{|c|c|c|c|c|c|c|c|}
\hline \multirow[b]{2}{*}{ Entry } & \multirow[b]{2}{*}{ Solvent } & \multicolumn{4}{|c|}{ Kinetics of Enantiomerization } & \multirow[b]{2}{*}{ Dielectric Constant } & \multirow[b]{2}{*}{$t_{1 / 2}$ at $25^{\circ} \mathrm{C}^{\mathrm{a}}$} \\
\hline & & $k\left(\mathrm{~s}^{-1}\right)$ & $\Delta \mathrm{G}^{\neq}(\mathrm{kJ} / \mathrm{mol})$ & $\mathbf{T}\left({ }^{\circ} \mathbf{C}\right)$ & $t_{1 / 2}$ (at T) & & \\
\hline 1 & $\mathrm{H}_{2} \mathrm{O}$ & nd & $<90$ & 20 & $<5 \min$ & 78.4 & $<5 \min$ \\
\hline 2 & $\mathrm{MeCN}$ & nd & $<90$ & 20 & $<5 \mathrm{~min}$ & 37.5 & $<5 \min$ \\
\hline 3 & $\mathrm{MeOH}$ & $4.8510^{-5}$ & 96.7 & 22 & $2 \mathrm{~h}$ & 32.6 & $1 \mathrm{~h} 20 \mathrm{~min}$ \\
\hline 4 & $\mathrm{EtOH}$ & $9.0510^{-6}$ & 100.8 & 22 & $10.6 \mathrm{~h}$ & 25.3 & $7 \mathrm{~h}$ \\
\hline 5 & $i-\mathrm{PrOH}$ & $1.7210^{-5}$ & 99.2 & 22 & $5.6 \mathrm{~h}$ & 20.2 & $4 \mathrm{~h}$ \\
\hline 6 & MTBE & $4.7710^{-5}$ & 107.8 & 55 & $2 \mathrm{~h}$ & & $5 \mathrm{~d}$ \\
\hline 7 & THF & $5.8410^{-6}$ & 117.4 & 66 & $16.5 \mathrm{~h}$ & 7.4 & $239 \mathrm{~d}$ \\
\hline 8 & $\mathrm{CHCl}_{3}$ & $4.9310^{-7}$ & 122.9 & 62 & $8 \mathrm{~d}$ & 4.81 & $6 y$ \\
\hline 9 & Ethyl acetate & $1.3910^{-6}$ & 125.5 & 77 & $69 \mathrm{~h}$ & 6 & $17 \mathrm{y}$ \\
\hline 10 & Toluene & $1.7210^{-5}$ & 129.6 & 110 & $10 \mathrm{~h}$ & 2.38 & $90 \mathrm{y}$ \\
\hline
\end{tabular}

${ }^{a}$ Estimated with the hypothesis that the enantiomerization barrier is constant with temperature.

separation and isolation. Therefore, we were quite surprised to discover that in aqueous solution, the enantiomers $\mathbf{1 5}$ are utterly configurationally unstable with the racemization rate being so fast that it cannot be even accurately measured using the present approach. All we could do was the estimation that the enantiomerization proceeds with $\Delta \mathrm{G}^{\neq}$less than $90 \mathrm{~kJ} / \mathrm{mol}$ with $t_{1 / 2}$ racemization less than 5 minutes (entry 1 ). The same results were observed conducting the experiments in solutions of acetonitrile (entry 2), indicating some generality in the configurational instability of enantiomers $\mathbf{1 5}$ in highly polar solvents. In sharp contrast to water (entry 1) and acetonitrile (entry 2), the experiments performed in alcoholic solutions (entries 3-5) were very successful allowing for a complete description of the enantiomerization process. Thus, in the methanol, we determined the following data: $k_{\text {enantiomerization }}=4.8510^{-5} \mathrm{~s}^{-1}\left(22^{\circ} \mathrm{C}\right.$, methanol $)$ with the 
$\Delta \mathrm{G}^{\neq}$equal $96.7 \mathrm{~kJ} / \mathrm{mol}$, indicating that $t_{1 / 2}$ racemization for enantiomers 15 is only 1 hour and 20 minutes (entry 3). The experiments performed in ethanol revealed noticeably greater configurational stability of $\mathbf{1 5}$ as compared with that of methanol. Thus, the data obtained (entry 4) $k_{\text {enantiomerization }}=9.0510^{-6} \mathrm{~s}^{-1}\left(22^{\circ} \mathrm{C}\right.$, ethanol $)$ with the $\Delta \mathrm{G}^{\neq}=100.8 \mathrm{~kJ} / \mathrm{mol}$ indicated that $t_{1 / 2}$ racemization for enantiomers $\mathbf{1 5}$ is 7 hours. Similar data were obtained in the experiments conducted in isopropanolic solutions (entry 5). In this case, the $k_{\text {enantiomerization }}=1.7210^{-5} \mathrm{~s}^{-1}\left(22^{\circ} \mathrm{C}\right.$, isopropanol) with the $\Delta \mathrm{G}^{\neq}=99.2 \mathrm{~kJ} / \mathrm{mol}$ and $t_{1 / 2}$ racemization for enantiomers 15 making 4 hours.

Careful analysis of these data (entries 1-5) allowed us to notice that configurational stability of enantiomers $\mathbf{1 5}$ can be roughly correlated with the polarity of the solvent used, in particular its dielectric constant value. This prompted us to continue our study using other types of organic solvents. Thus, next set of experiments was conducted in ether-type solvents. Quite surprisingly, in MTBE, the configurational stability of enantiomers $\mathbf{1 5}$ was found to be noticeably increased making it necessary to elevate the experimental temperature from $22^{\circ} \mathrm{C}$ to $55^{\circ} \mathrm{C}$ (entry 6). In particular,

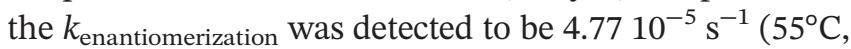
MTBE) with the $\Delta \mathrm{G}^{\neq}=107.8 \mathrm{~kJ} / \mathrm{mol}$, which corresponds to $t_{1 / 2}$ racemization for enantiomers 15 of 5 days. In another ether-type solvent, THF (entry 7), the configurational stability of enantiomers $\mathbf{1 5}$ was found to be markedly greater. As one can see from entry 7 , the experiments were conducted at $66^{\circ} \mathrm{C}$, recording $k_{\text {enantiomerization }}=5.8410^{-6} \mathrm{~s}^{-1}$ $\left(66^{\circ} \mathrm{C}, \mathrm{THF}\right)$ affording the $\Delta \mathrm{G}^{\neq}=117.4 \mathrm{~kJ} / \mathrm{mol}$ making the $t_{1 / 2}$ racemization for enantiomers 15 equivalent of 239 days. Inspired by these unexpected results, we selected yet another three common organic solvents presented in entries 8 to 10. Thus, in chloroform (entry 8), the experiments were conducted at nearly the solvent boiling point and gave the following values: $k_{\text {enantiomerization }}=4.9310^{-7} \mathrm{~s}^{-1}\left(62^{\circ} \mathrm{C}\right.$, chloroform $)$, $\Delta \mathrm{G}^{\neq}=122.9 \mathrm{~kJ} / \mathrm{mol}, t_{1 / 2}$ racemization for enantiomers $\mathbf{1 5}$ equaling astounding 6 years. In ethyl acetate, possessing a higher boiling point, we conducted experiments at $77^{\circ} \mathrm{C}$ allowing to record the $k_{\text {enantiomerization }}=1.3910^{-6} \mathrm{~s}^{-1}$ ( $77^{\circ} \mathrm{C}$, ethyl acetate), $\Delta \mathrm{G}^{\neq}=125.5 \mathrm{~kJ} / \mathrm{mol}$ leading to $t_{1 / 2}$ racemization for enantiomers $\mathbf{1 5}$ of stunning 17 years. Finally, the experiment conducted in toluene, again at nearly the solvent boiling point, revealed extraordinary level of enantiomers $\mathbf{1 5}$ configurational stability, $k_{\text {enantiomerization }}=1.7210^{-5} \mathrm{~s}^{-1}\left(110^{\circ} \mathrm{C}\right.$, toluene $)$, $\Delta \mathrm{G}^{\neq}=129.6 \mathrm{~kJ} / \mathrm{mol}$. The calculated $t_{1 / 2}$ racemization for enantiomers $\mathbf{1 5}$ in toluene equalled of 90 years.

The observed range, from $\Delta \mathrm{G}^{\neq}=<90$ to $129.6 \mathrm{~kJ} / \mathrm{mol}$, with $t_{1 / 2}$ less than 5 minutes to 90 years, of the configurational stability of the stereogenic nitrogen in $\mathrm{Ni}$ (II) complexes 15 was, to say the least, totally unexpected. It should be noted that we failed to find in the literature any analogs or precedents to this trend observed for compounds with nitrogen stereogenic center. Therefore, we believe that these results obviously present a novel phenomenon of greater scientific and practical importance.

Some rationalization of the results obtained can be outlined using the chain of reactions presented in Scheme 3.

The broad literature data on the ligand exchange mechanisms at metal centers ${ }^{27}$ adopt a typical associative nucleophile-coordination-N-discoordination mechanism ${ }^{28}$ via formation of $\mathrm{N}-\mathrm{Ni}$-noncoordinated intermediate $\mathbf{1 6}$. This mechanism would perfectly support the results obtained in such solvents as water (entry 1), acetonitrile (entry 2), and alcohols (entries 3-5). To some extent, the ethers (entries 6 and 7) and ethyl acetate (entry 9) can be considered as possessing nucleophilic groups with an ability to coordinate to the $\mathrm{Ni}(\mathrm{II})$. On the other hand, chloroform (entry 8) and toluene (entry 10) would hardly act as nucleophiles coordinating to the metal. Thus, the question of configurational stability of stereogenic nitrogen has to be always asked in context of the reaction conditions, in particular a solvent or presence of any other nucleophiles. For example, stereogenic nitrogen center of compound $\mathbf{1 5}$ in water is very configurationally unstable and can be somehow disregarded as an element of chirality in aqueous medium. In sharp contrast, the configurational stability of nitrogen in $\mathbf{1 5}$ in nonnucleophilic medium is exceptionally high and can be used for synthetic purposes as a stable element of stereochemical information. Nevertheless, the data obtained in this work show more complex relationships between the configurational stability and the solvent nucleophilicity. For instance, in the alcohols series (entries 3-5), the dependence of the observed $\Delta \mathrm{G}^{\neq}$and dielectric constant of the solvents are not linear, suggesting some role of steric effects or other factors. Similar discrepancy can be seen in the ethers series (entries 6 and 7) where the difference in the observed $\Delta G^{\neq}$cannot be accounted for simply by nucleophilic considerations. Also, ethyl acetate (entry 9), possessing somehow nucleophilic oxygens, was found to perform more likely total nonnucleophilic solvent. Evidently, further design of model compounds of type

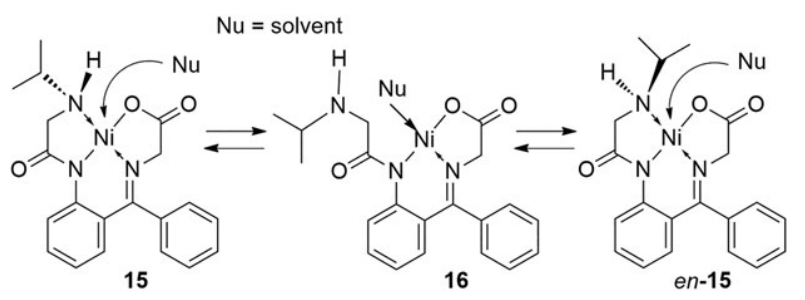

SCHEME 3 Proposed nucleophile-assisted mechanism for the racemization of $\mathrm{Ni}(\mathrm{II})$ complex $\mathbf{1 5}$ 
15 with controllable steric and electronic factors is highly desirable for more detailed study of this phenomenon. Furthermore, as suggested by one of the referees, a relationship could be considered between $\Delta \mathrm{G}^{\neq}$and solvent coordination capacity ${ }^{29}$ and $\mathrm{pKa}$.

\section{4 | CONCLUSION}

We demonstrate that the properly designed $\mathrm{Ni}(\mathrm{II})$ complex of glycine Schiff base possessing single-nitrogen stereogenic center can be successfully used to assess its configurational stability via HPLC-assisted kinetic racemization experiments. We show that the configurational stability of the $\mathrm{Ni}(\mathrm{II})$-coordinated nitrogen is a function of solvent, more generally reaction conditions, and can range from insignificant ( $t_{1 / 2}$ less than $5 \mathrm{~min}$ ) to quite stable $\left(t_{1 / 2} 90 \mathrm{y}\right)$. The data reported in this study allow for rational prediction of the stereochemical properties of the stereogenic nitrogen coordinated to $\mathrm{Ni}(\mathrm{II})$ and would be quite helpful in the design of new chiral ligands as well as reaction conditions and synthetic strategy. As suggested by one of the referees, further exploration of this approach using structurally diverse $\mathrm{Ni}(\mathrm{II})$ complex models and various conditions is currently under consideration and will be reported in a due course.

1. a)Henninot A, Collins JC, Nuss JM. The current state of peptide drug discovery: back to the future? J Med Chem. 2018;61(4):1382-1414. b)Blaskovich MAT. Unusual amino acids in medicinal chemistry. J Med Chem. 2016;59(24):10807-10836. c)Soloshonok VA, Izawa K (Eds). Asymmetric Synthesis and Application of Alpha-Amino Acids, ACS Symposium Series 1009. Oxford University Press; 2009.

2. For the definition of tailor-made amino acids, see: Soloshonok V A, Cai C, Hruby V J, Meervelt L V, Asymmetric synthesis of novel highly sterically constrained (2S,3S)-3-methyl-3-trifluoromethyland (2S,3S,4R)-3-trifluoromethyl-4-methylpyroglutamic acids. Tetrahedron 1999:55:12045-12058, 41.

3. a)Gante J. Peptidomimetics-tailored enzyme inhibitors. Angew Chem Int Ed Engl. 1994;33(17):1699-1720. b)Hruby V, Balse P. Conformational and topographical considerations in designing agonist peptidomimetics from peptide leads. Curr Med Chem. 2000;7(9):945-970. c)Vagner J, Qu H, Hruby VJ. Peptidomimetics, a synthetic tool of drug discovery. Curr Opin Chem Biol. 2008;12(3):292-296. d)Cai M, Cai C, Mayorov AV, et al. Biological and conformational study of $\beta$-substituted prolines in MT-II template: steric effects leading to human MC5 receptor selectivity. J Pept Res. 2004;63(2):116-131. e)Qiu W, Gu X, Soloshonok VA, Carducci MD, Hruby VJ. Stereoselective synthesis of conformationally constrained reverse turn dipeptide mimetics. Tetrahedron Lett. 2001;42(2):145-148.

4. a)Ma JS. Unnatural amino acids in drug discovery. Chim Oggi. 2003;21:65-68. b)Hodgson DRW, Sanderson JM. The synthesis of peptides and proteins containing non-natural amino acids. Chem Soc Rev. 2004;33(7):422-430. c)Sato T, Izawa K, Aceña JL, Liu H, Soloshonok VA. Tailor-made $\alpha$-amino acids in the pharmaceutical industry: synthetic approaches to (1R,2S)-1amino-2-vinylcyclopropane-1-carboxylic acid (vinyl-ACCA). Eur J Org Chem. 2016;2016(16):2757-2774. d)Sorochinsky AE, Aceña JL, Moriwaki H, Sato T, Soloshonok VA. Asymmetric synthesis of $\alpha$-amino acids via homologation of $\mathrm{Ni}$ (II) complexes of glycine Schiff bases; part 1: alkyl halide alkylations. Amino Acids. 2013;45(4):691-718.

5. a)Lovering F. Escape from Flatland 2: complexity and promiscuity. Med Chem Commun. 2013;4(3):515-519. b)Fosgerau K, Hoffmann T. Peptide therapeutics: current status and future directions. Drug Discov Today. 2015;20(1):122-128. c)Craik DJ, Fairlie DP, Liras S, Price D. The future of peptide-based drugs. Chem Biol Drug Des. 2013;81(1):136-147. d)Wang S, Wang Y, Wang J, et al. The second-generation of highly potent hepatitis $\mathrm{C}$ virus (HCV) NS3/4A protease inhibitors: evolutionary design based on tailor-made amino acids, synthesis and major features of bio-activity. Curr Pharm Des. 2017;23(30):4493-4554.

6. For recent reviews, see:a)So SM, Kim H, Mui L, Chin J. Mimicking nature to make unnatural amino acids and chiral diamines. Eur J Org Chem. 2012;229-241. b)Metz AE, Kozlowski MC. Recent advances in asymmetric catalytic methods for the formation of acyclic $\alpha, \alpha$-disubstituted $\alpha$-amino acids. J Org Chem. 2015;80(1):1-7. c)He G, Wang B, Nack WA, Chen G. Syntheses and transformations of $\alpha$-amino acids via palladium-catalyzed auxiliary-directed sp3C-H functionalization. Acc Chem Res. 2016;49(4):635-645. d)Sorochinsky AE, Aceña JL, Moriwaki H, Sato T, Soloshonok V. Asymmetric synthesis of $\alpha$-amino acids via homologation of Ni (II) complexes of glycine Schiff bases. Part 2: aldol, Mannich addition reactions, deracemization and (S) to (R) interconversion of $\alpha$-amino acids. Amino Acids. 2013;45(5):1017-1033. e)Aceña JL, Sorochinsky AE, Soloshonok V. Asymmetric synthesis of $\alpha$-amino acids via homologation of Ni (II) complexes of glycine Schiff bases. Part 3: Michael addition reactions and miscellaneous transformations. Amino Acids. 2014;46(9):2047-2073. f)Soloshonok V, Sorochinsky A. Practical methods for the synthesis of symmetrically $\alpha, \alpha$ disubstituted $\alpha$-amino acids. Synthesis. 2010;2010(14):2319-2344. 
7. a)Aceña JL, Sorochinsky AE, Moriwaki H, Sato T, Soloshonok VA. Synthesis of fluorine-containing $\alpha$-amino acids in enantiomerically pure form via homologation of $\mathrm{Ni}$ (II) complexes of glycine and alanine Schiff bases. $J$ Fluor Chem. 2013;155:21-38. b)Mikami K, Fustero S, Sánchez-Roselló M, Aceña J, Soloshonok VA. Synthesis of fluorinated $\beta$-amino acids. Synthesis. 2011;2011(19):3045-3079.

8. Grygorenko OO, Biitseva AV, Zhersh S. Amino sulfonic acids, peptidosulfonamides and other related compounds. Tetrahedron. 2018;74(13):1355-1421.

9. a)Röschenthaler GV, Kukhar VP, Kulik IB, et al. Asymmetric synthesis of phosphonotrifluoroalanine and its derivatives using n-tert-butanesulfinyl imine derived from fluoral. Tetrahedron Lett. 2012;53(5):539-542. b)Turcheniuk KV, Poliashko KO, Kukhar VP, Rozhenko AB, Soloshonok VA, Sorochinsky AE. Efficient asymmetric synthesis of trifluoromethylated $\beta$ aminophosphonates and their incorporation into dipeptides. Chem Commun. 2012;48(94):11519-11521.

10. a)Soloshonok VA, Ohkura H, Yasumoto M. Operationally convenient asymmetric synthesis of (S)- and (R)-3-amino-4,4,4trifluorobutanoic acid. J Fluor Chem. 2006;127(7):930-935. b) Shibata N, Nishimine T, Shibata N, et al. Organic basecatalyzed stereodivergent synthesis of (R)- and (S)-3-amino4,4,4-trifluorobutanoic acids. Chem Commun. 2012;48(34):4124-4126. c)Yamada T, Okada T, Sakaguchi K, Ohfune Y, Ueki H, Soloshonok VA. Efficient asymmetric synthesis of novel 4-substituted and configurationally stable analogues of thalidomide. Org Lett. 2006;8(24):5625-5628.

11. a)Sorochinsky AE, Aceña JL, Soloshonok VA. Self-disproportionation of enantiomers of chiral, non-racemic fluoroorganic compounds: role of fluorine as enabling element. Synthesis. 2013;45:141-152. b)Ueki H, Yasumoto M, Soloshonok VA. Rational application of self-disproportionation of enantiomers via sublimation-a novel methodological dimension for enantiomeric purifications. Tetrahedron: Asymmetry. 2010;21(1112):1396-1400.

12. Wang Y, Song X, Wang J, Moriwaki H, Soloshonok VA, Liu H. Recent approaches for asymmetric synthesis of $\alpha$-amino acids via homologation of $\mathrm{Ni}$ (II) complexes. Amino Acids. 2017;49(9):1487-1520.

13. Soloshonok VA, Ellis TK, Ueki H, Ono T. Resolution/ deracemization of chiral-amino acids using resolving reagents with flexible stereogenic centers. $J$ Am Chem Soc. 2009;131(21):7208-7209.

14. Zhou S, Wang J, Chen X, Aceña JL, Soloshonok VA, Liu H. Chemical kinetic resolution of unprotected b-substituted-bamino acids using recyclable chiral ligands. Angew Chem Int Ed. 2014;53(30):7883-7886.

15. a)Tang X, Soloshonok VA, Hruby VJ. Convenient asymmetric synthesis of enantiomerically pure $2^{\prime}, 6^{\prime}$-dimethyltyrosine (DMT) via alkylation of chiral nucleophilic glycine equivalent. Tetrahedron: Asymmetry. 2000;11(14):2917-2925. b)Taylor SM, Yamada T, Ueki H, Soloshonok VA. Asymmetric synthesis of enantiomerically pure 4-aminoglutamic acids via methylenedimerization of chiral glycine equivalents with dichloromethane under operationally convenient conditions. Tetrahedron Lett. 2004;45(50):9159-9162.
16. Soloshonok VA, Ueki H, Tiwari R, Cai C, Hruby VJ. Virtually complete control of simple and face diastereoselectivity in the Michael addition reactions between achiral equivalents of a nucleophilic glycine and (S)- or (R)-3-(e-enoyl)-4-phenyl-1,3oxazolidin-2-ones: practical method for preparation of $\beta$ substituted pyroglutamic acids and prolines. J Org Chem. 2004;69(15):4984-4990.

17. a)Soloshonok VA, Kukhar VP, Galushko SV, et al. General method for the synthesis of enantiomerically pure $\beta$-hydroxy- $\alpha$ amino acids, containing fluorine atoms in the side chains. Case of stereochemical distinction between methyl and trifluoromethyl groups. X-ray crystal and molecular structure of the nickel (II) complex of (2S,3S)-2-(trifluoromethyl)threonine. J Chem Soc Perkin Trans. 1993;1:3143-3155. b)Kawamura A, Moriwaki H, Röschenthaler G-V, Kawada K, Aceña JL, Soloshonok VA. Synthesis of (2S,3S)- $\beta$-(trifluoromethyl)- $\alpha, \beta$-diamino acid by Mannich addition of glycine Schiff base Ni (II) complexes to ntert-butylsulfinyl-3,3,3-trifluoroacetaldimine. J Fluorine Chem. 2015;171:67-72.

18. a)Soloshonok VA, Ueki H, Ellis TK, Yamada T, Ohfune Y. Application of modular nucleophilic glycine equivalents for truly practical asymmetric synthesis of $\beta$-substituted pyroglutamic acids. Tetrahedron Lett. 2005;46(7):1107-1110. b)Ellis TK, Ueki H, Yamada T, Ohfune Y, Soloshonok VA. The design, synthesis and evaluation of a new generation of modular nucleophilic glycine equivalents for the efficient synthesis of sterically constrained $\alpha$-amino acids. J Org Chem. 2006;71(22):8572-8578.

19. Nian Y, Wang J, Zhou S, et al. Recyclable ligands for the nonenzymatic dynamic kinetic resolution of challenging $\alpha$-amino acids. Angew Chem Int Ed. 2015;54(44):12918-12922.

20. Takeda R, Kawamura A, Kawashima A, et al. Chemical dynamic kinetic resolution and (S)/(R)-interconversion of unprotected $\alpha$-amino acids. Angew Chem Int Ed. 2014;53(45):12214-12217.

21. Jörres M, Chen X, Aceña JL, et al. Asymmetric synthesis of $\alpha$ amino acids under operationally convenient conditions. $A d v$ Synth Catal. 2014;356(10):2203-2208.

22. a)Bergagnini M, Fukushi K, Han J, et al. NH-type of chiral Ni (II) complexes of glycine Schiff base: design, structural evaluation, reactivity and synthetic applications. Org Biomol Chem. 2014;12(8):1278-1291. b)Moriwaki H, Resch D, Li H, et al. Inexpensive chemical method for preparation of enantiomerically pure phenylalanine. Amino Acids. 2014;46(4):945-952.

23. a)Takeda R, Kawamura A, Kawashima A, et al. Second-order asymmetric transformation and its application for the practical synthesis of $\alpha$-amino acids. Org Biomol Chem. 2018;16(27):4968-4972. b)Takeda R, Kawashima A, Yamamoto $\mathrm{J}$, et al. Tandem alkylation-second-order asymmetric transformation protocol for preparation of phenylalanine-type tailormade $\alpha$-amino acids. ACS Omega. 2018;3(8):9729-9737.

24. Vanthuyne NC, Roussel C. Chiroptical detectors for the study of unusual phenomena in chiral chromatography. Different Enantio I. 2013;340:107-151.

25. Moore JL, Taylor SM, Soloshonok VA. An efficient and operationally convenient general synthesis of tertiary amines by direct alkylation of secondary amines with alkyl halides in the presence of Hünig's base. Arkivoc. 2005;6:287-292. 
26. Zhang W, Eto Ekomo R, Roussel C, et al. Axially chiral Ni (II) complexes of $\alpha$-amino acids; separation of enantiomers and kinetics of racemization. Chirality. 2018;30(4):498-508.

27. a)Hall C, Perutz RN. Transition metal alkane complexes. Chem Rev. 1996;96(8):3125-3146. b)Richens DT. Ligand substitution reactions at inorganic centers. Chem Rev. 2005;105(6):1961-2002.

28. a)Reedijk I. Metal-ligand exchange kinetics in platinum and ruthenium complexes. Platinum Metals Rev. 2008;52(1):2-11. b) Snee PT, Shanoski J, Harris CB. Mechanism of ligand exchange studied using transition path sampling. J Am Chem Soc. 2005;127(4):1286-1290. c)Perutz RN, Turner JJ. Photochemistry of the group 6 hexacarbonyls in low-temperature matrices. III. Interaction of the pentacarbonyls with noble gases and other matrices. J Am Chem Soc. 1975;97(17):4791-4800. d)Yang GK, Viada V, Peters KS. Application of time-resolved photoacoustic calorimetry to $\mathrm{Cr}-\mathrm{L}$ bond enthalpies in $\mathrm{Cr}(\mathrm{CO})_{5}-\mathrm{L}$. Polyhedron. 1988;7(16-17):1619-1622. e)Hu SN, Farrell GJ, Cook C, Johnson R, Burkey TJ. Rearrangement of.eta.5-CpMn (CO) $2(\mathrm{HSiEt} 3)$ : a missing step in the energy surface for the oxidative addition of silane to $\mathrm{CpMn} \quad(\mathrm{CO})_{2}$ (heptane). Organometallics. 1994;13(11):4127-4128. f)Yang H, Asplund MC, Kotz KT, Wilkens MJ, Frei H, Harris CB. Reaction mechanism of silicon -hydrogen bond activation studied using femtosecond to nanosecond IR spectroscopy and ab initio methods. J Am Chem Soc. 1998;120(39):10154-10165. g)Geftakis S, Ball GE. Direct observation of a transition metal alkane complex, CpRe $(\mathrm{CO})_{2}$ (cyclopentane), using NMR spectroscopy. J Am Chem Soc. 1998;120(38):9953-9954.

29. Munakata M, Kitagawa S, Miyazima M. Classification of solvents based on their coordination power to nickel (II) ion. A new measure for solvent donor ability. Inorg Chem. 1985;11:1638-1643. 